\title{
Participant experiences from chronic administration of a multivitamin versus placebo on subjective health and wellbeing: a double-blind qualitative analysis of a randomised controlled trial
}

Jerome Sarris ${ }^{1,2}$, Katherine H M Cox ${ }^{2 *}$, David A Camfield ${ }^{2}$, Andrew Scholey ${ }^{2}$, Con Stough ${ }^{2}$, Erin Fogg ${ }^{2}$, Marni Kras ${ }^{2}$, David J White ${ }^{2,3}$, Avni Sali ${ }^{4}$ and Andrew Pipingas ${ }^{2}$

\begin{abstract}
Background: While many randomised controlled trials have been conducted on multivitamins, to our knowledge no qualitative research exploring the subjective experience of taking a multivitamin during a clinical trial has been reported.

Methods: Semi-structured and open-ended written questions were incorporated into a 16-week double-blind, randomised, placebo-controlled, parallel groups trial of once-daily multivitamin administration. At the final study visit (week 16), three open-ended questions were posed to elucidate any positive, negative or unusual experiences from taking either the multivitamin or matched placebo. Qualitative thematic analysis was undertaken by researchers who were blind as to treatment condition of participants, and triangulation (independent analysis from three researchers) was employed to ensure methodological rigour. Participant's experiences were categorised as "positive" or "negative" and a Chi Square analysis was then applied to each of the experiential themes, to compare experiences between the multivitamin and placebo groups, (subdividing the groups by gender). Usual experiences were categorised and discussed separately.

Results: Of the 182 participants enrolled, 116 completed the study and qualitative data were available from 114 participants. Thematic analysis revealed significant effects in favour of the multivitamin over placebo for participants experiencing increased energy levels $(p=.022)$ and enhanced mood $(p=.027)$. The beneficial effect on energy levels was particularly evident among female participants. A trend was found for participants reporting better sleep in the multivitamin over placebo. The multivitamin and placebo groups did not significantly differ in perceived positive or negative effects in areas relating to other aspects of mental function or physical health. No significant negative effects were revealed, although there was a non-significant trend for more people in the multivitamin group having minor digestive complaints.

(Continued on next page)
\end{abstract}

\footnotetext{
*Correspondence: kcox@swin.edu.au

${ }^{2}$ Centre for Human Psychopharmacology, Swinburne University of

Technology, Hawthorn, Australia

Full list of author information is available at the end of the article
} 
(Continued from previous page)

Conclusion: This represents the first documented qualitative investigation of participants' experience of chronic administration of a multivitamin. Results uncovered a range of subjective beneficial effects that are consistent with quantitative data from previously published randomised controlled trials examining the effects of multivitamins and B vitamin complexes on mood and well-being.

Trial registration: Prior to commencement this trial was registered with the Australian New Zealand Clinical Trials Registry (www.anzctr.org.au) ACTRN12611000092998

Keywords: Multivitamin, Mood, Energy, Cognition, Adverse reactions, Qualitative

\section{Background}

The use of multivitamin (MV) supplements has become increasingly popular among the general public [1]. There is growing literature to suggest that $\mathrm{MV}$ or multinutrient supplementation may have cognitive and/or mood benefits in children [2] and across the adult life span [3-10]. There are a numerous ingredients commonly found in MV and mineral supplements that may affect cognition and mood. Low B vitamin levels have been linked to increased levels of homocysteine, which can have a detrimental effect on cognition [11,12], and lowered levels of Vitamin B12 and folic acid have been associated with higher incidence of depression or depressed mood [13-15]. Vitamin $C$ may improve cognition, as a result of central antioxidant activity $[16,17]$. Vitamin D can improve mood [18], and supplementation may promote general health through its integral involvement in a vast number of biological processes [19]. Minerals such as zinc, magnesium and calcium influence neurotransmitter systems and therefore play an important role in maintaining healthy cognitive function and mood [20-22]. Additionally, though often present in small (and potentially sub-therapeutic) quantities in MVs, herbal ingredients such as Ginkgo biloba and Panax ginseng may reduce stress and anxiety [23,24] while Centella asiatica has exhibited mood enhancing effects [25].

The Swisse Ultivite F1 multivitamin ${ }^{\circledR}$ (SMV) contains a proprietary blend of vitamins at levels exceeding recommended daily intakes (which are arguably low), minerals, as well as low doses of a range of medicinal herbs. Previous studies from our laboratory have identified beneficial effects of SMV use in older populations. Harris et al. [7] found that an 8-week supplementation with Men's SMV in males aged 50-69 years was associated with a significant reduction in symptoms of depression and anxiety and an improvement in alertness and general health, that were not seen in the placebo group. The same treatment was associated with improvements in contextual recognition memory performance in men aged between 50 and 74 years who had a sedentary lifestyle [10]. Macpherson et al. [26], also showed that 16-week supplementation with a SMV formula designed for older women $\left(50+\right.$ Ultivite $\left.^{\circledR}\right)$ was associated with faster speed of spatial working memory performance.

The present 16-week double-blind randomised controlled trial (RCT) sought to extend these findings to younger individuals aged $20-50$ years and to test once daily Swisse Men's and Women's Ultivite ${ }^{\circledR}$ multinutrient supplements. The clinical trial assessed the effect of the SMV on cognition, and on psychological attributes such as mood, stress, sleep, and energy levels. The study also utilised a "mixed-methods" approach employing both quantitative and qualitative methodological techniques (the quantitative analyses are reported elsewhere). Qualitative measures may form the focus of a study, or be part of a combined approach whereby a qualitative component augments the quantitative mainstay of an RCT [27-29]. These measures can assist to understand participants' experiences of an intervention in an RCT [27-29]. This approach can help to develop hypotheses for future research, and may identify previously unknown therapeutic benefits or side-effects. To our knowledge qualitative methodology has not previously been used in RCTs of MVs. It is important to note that while there is a key difference between reductive statistically-based quantitative research and exploratory experiential qualitative research, in order to maintain methodological rigour, it is possible to conduct qualitative research in a double-blinded manner, with neither the participants nor the researchers who analyse the data knowing which participants received the active or placebo intervention.

In this paper we present the qualitative component of the study (analysed via quantitative methodology) which explores participants personal experiences of being chronically administered a MV compared to placebo.

\section{Methods}

\section{Overview}

Eligible consenting adults participated in a 16-week double-blind RCT involving once daily administration of SMV tablet or matching placebo. Participants attended three testing sessions at the Centre for Human Psychopharmacology at Swinburne University in Melbourne, at baseline, 8-weeks and 16-weeks, for the assessment of 
wellbeing, mood, stress and cognition. Potential biological mechanisms of action were also examined. The study was granted ethical approval by the Swinburne University of Technology Ethics Human Ethics Committee (SUHREC Project 2010/261) and was registered with the Australian New Zealand Clinical Trials Registry (ANZCTR no: ACTRN12611000092998) prior to commencement.

\section{Participants}

Recruitment was carried out from February to August 2011 and was facilitated via adverts in newspapers and flyers, radio, television, and social media. Inclusion criteria required participants who were healthy, nonsmoking males and females aged 20 to 50 years who were currently engaged in at least part-time employment and/or undertaking a higher education or technical college course. They had no history of head injury or stroke, psychiatric or neurologic conditions, heart disease or diabetes and had no present kidney, liver or gastrointestinal conditions that might impair food metabolism. They were also free from any known or suspected food allergies. Individuals were ineligible to participate if they were pregnant or taking any form of herbal or vitamin supplement or over the counter or prescription medications (with the exception of the oral contraception pill).

\section{Treatments, randomisation and blinding}

The treatment received (depending on gender) was either Swisse Men's Ultivite $F 1^{\circledR} /$ Swisse Women's Ultivite F1 ${ }^{\circledR}(\mathrm{SMV})$ or matching placebo. The contents of the men's and women's SMV preparations are shown in Tables 1 and 2 respectively. Both contain a blend of vitamins at levels exceeding recommended daily intakes (RDI) [30] including B vitamins (e.g. Thiamin approx. 2500-4500\% RDI, Riboflavin approx. 2300\%-4545\% RDI, Niacin approx. 185\%-355\% RDI, Pantothenic acid approx. 1070\%-1700\% adequate intake, B6 approx. 1900\%-3165\% RDI and B12 approx. 1250\%-2080\% RDI) and vitamins $\mathrm{C}$ (approx. 365\% RDI), D (100\% RDI) and E (approx. 330\%-475\% RDI), as well as minerals such as calcium, magnesium, potassium and iron. They also contain a range of antioxidants and extracts equivalent to approximately $2.6-3 \mathrm{~g}$ of medicinal herbs including Ginkgo biloba, Vitis vinifera, Silybum marianum and Camellia sinensis. Though the two formulations are predominantly equivalent the amount of some nutrients varies slightly, for example the women's formula contains higher levels of calcium and iron, and there are a small number of herbal or plant extracts unique to either preparation. The placebo tablets were the same size and colour as the SMV tablets and contained starch and a small amount of riboflavin (2mg) designed to give a similar smell and colouration of the urine.

Treatment randomisation was independently carried out, separately for males and females, in blocks of four by the supplier; Swisse Vitamins Pty Ltd. Treatments were assigned a treatment identification number and packaged in identical boxes containing 18 blister packs of 7 tablets (18 x week supply). The extra 2-week supply of tablets was included to ensure continuous treatment in the event of late return visits and to aid in the assessment of treatment compliance. Following baseline assessment, randomised participants were provided with the treatment and instructed to take one tablet daily with, or immediately following breakfast for the next 16 weeks, and to bring all unused tablets to each study visit. Data were unblinded only after all data were finalised and preliminary analyses were complete.

\section{Procedure}

Participants attended a brief practice session during which written consent was obtained, eligibility was confirmed and they were familiarised with all study measures. Demographic characteristics that may have modified outcomes were recorded, including age, education and BMI and measures of trait anxiety (State-Trait Anxiety Inventory) [31], depression (Beck Depression Inventory - II) [32] and intelligence (WASI Matrix reasoning task) [33] were completed. Three testing sessions were undertaken: at baseline, Week 8 and Week 16. As this trial was concerned with chronic effects of supplementation, participants were asked to abstain from taking their tablet on the morning of testing sessions. This avoided any potentially confounding acute effects that a single day's treatment may have had on assessments and which could not have been differentiated from the chronic effects of repeated and prolonged supplementation.

Participants completed standardised assessments of wellbeing, mood and stress, and a computerised cognitive test battery. Blood measures, cardiovascular function and salivary cortisol levels were investigated as potential mechanisms of action. In total, each testing session lasted approximately 3 hours. A researcher from the Centre of Human Psychopharmacology at Swinburne University of Technology administered all tests. The number of tablets returned was used to calculate total treatment compliance, with participants being required to be at least $80 \%$ compliant for inclusion of their data in analyses.

\section{Qualitative assessment component}

In addition to mood, cognitive and biomarker assessments, at the conclusion of the final testing session (week 16), participants were presented with three 
Table 1 Men's SMV preparation contents

\begin{tabular}{|c|c|}
\hline Component & Daily dose \\
\hline Betacarotene & $5 \mathrm{mg}$ \\
\hline Vitamin D3 & $2001 \mathrm{U}$ \\
\hline Vitamin E & $501 \mathrm{U}$ \\
\hline Vitamin B1 & $30 \mathrm{mg}$ \\
\hline Vitamin B2 & $30 \mathrm{mg}$ \\
\hline Nicotinamide & $30 \mathrm{mg}$ \\
\hline Vitamin B5 & $64.13 \mathrm{mg}$ \\
\hline Vitamin B6 & $24.68 \mathrm{mg}$ \\
\hline Vitamin B12 & $30 \mathrm{mg}$ \\
\hline Biotin & $50 \mathrm{mcg}$ \\
\hline Folic acid & $500 \mathrm{mcg}$ \\
\hline Vitamin C & $165.2 \mathrm{mg}$ \\
\hline Choline bitartrate & $25 \mathrm{mg}$ \\
\hline Inositol & $25 \mathrm{mg}$ \\
\hline Citrus bioflavonoid extract & $40 \mathrm{mg}$ \\
\hline Tyrosine & $1 \mathrm{mg}$ \\
\hline Lysine & $50 \mathrm{mg}$ \\
\hline Calcium & $21 \mathrm{mg}$ \\
\hline Magnesium & $57.89 \mathrm{mg}$ \\
\hline Potassium & $4 \mathrm{mg}$ \\
\hline Iron & $3 \mathrm{mg}$ \\
\hline Chromium & $6.2 \mathrm{mcg}$ \\
\hline Manganese & $1.2 \mathrm{mg}$ \\
\hline Copper & $28 \mathrm{mcg}$ \\
\hline lodine & $50 \mathrm{mcg}$ \\
\hline Zinc & $6 \mathrm{mg}$ \\
\hline Selenium & $26 \mathrm{mcg}$ \\
\hline Co-Enzyme Q10 & $1 \mathrm{mg}$ \\
\hline Spearmint oil & $1.5 \mathrm{mg}$ \\
\hline Parsley & $10 \mathrm{mg}$ \\
\hline Papaya & $10 \mathrm{mg}$ \\
\hline Lutein & $200 \mathrm{mcg}$ \\
\hline Celery & $20 \mathrm{mg}$ \\
\hline Astragalus & $50 \mathrm{mg}$ \\
\hline Buchu & $10 \mathrm{mg}$ \\
\hline Barberry & $15 \mathrm{mg}$ \\
\hline Gotu kola & $50 \mathrm{mg}$ \\
\hline Hawthorn & $100 \mathrm{mg}$ \\
\hline Horsetail & $30 \mathrm{mg}$ \\
\hline Fennel & $15 \mathrm{mg}$ \\
\hline Sarsparilla & $50 \mathrm{mg}$ \\
\hline Damiana & $120 \mathrm{mg}$ \\
\hline Ginger & $5 \mathrm{mg}$ \\
\hline Globe artichoke & $50 \mathrm{mg}$ \\
\hline
\end{tabular}

Table 1 Men's SMV preparation contents (Continued)

\begin{tabular}{ll}
\hline Oats & $500 \mathrm{mg}$ \\
Bilberry & $25 \mathrm{mg}$ \\
Grape seed & $1 \mathrm{~g}$ \\
St Mary's thistle & $50 \mathrm{mg}$ \\
Korean ginseng & $50 \mathrm{mg}$ \\
Ginkgo & $100 \mathrm{mg}$ \\
Saw Palmetto & $200 \mathrm{mg}$ \\
Green tea & $20 \mathrm{mg}$ \\
Tomato & $700 \mathrm{mg}$ \\
\hline
\end{tabular}

written, semi-structured, open-ended qualitative questions. Pre-study, a pilot form was constructed via a consensus between researchers, being tested on a sample of colleagues for feedback on the utility of its format. In response to the feedback the form was slightly modified by consolidating questions into three major areas of enquiry. For each question, participants were directed to indicate whether or not they perceived any direct effects from taking the tablets, and if so to describe their experience in as much detail as possible.

The questions were as follows:

1) "In the past month describe any positive effects (if any) on your physical or mental health (mood, stress, brain function) that you think may have occurred due to taking the tablets."

2) "In the past month describe any negative effects (if any) on your physical or mental health (mood, stress, brain function) that you think may have occurred due to taking the tablets."

3) "If apparent, please describe any unusual effects that you think may have occurred from taking the tablets."

\section{Data analysis}

As this was a double-blind study neither the study researchers or the participants were aware of what treatment the participant had been receiving. After the study was completed and the data were available for analysis, the question transcripts were read by two researchers and coded according to a grounded theory approach to data analysis. Initially, participants' experiences were separated into "positive" and "negative" effects. Following this, two major domains (mental/cognitive and physical) were categorised, within which many distinct themes were identified via a thematic analytic approach. Each reported experience was then coded under a theme heading by the researchers in a blinded manner. The themes were then submitted to researcher triangulation (whereby the three researchers provided independent readings of the written responses, with any divergences of interpretation discussed until resolution is reached). 
Table 2 Women's SMV preparation contents

\begin{tabular}{|c|c|}
\hline Component & Daily dose \\
\hline Betacarotene & $5 \mathrm{mg}$ \\
\hline Vitamin D3 & $2001 \mathrm{U}$ \\
\hline Vitamin E & $501 \mathrm{U}$ \\
\hline Vitamin B1 & $50 \mathrm{mg}$ \\
\hline Vitamin B2 & $50 \mathrm{mg}$ \\
\hline Nicotinamide & $50 \mathrm{mg}$ \\
\hline Vitamin B5 & $68.7 \mathrm{mg}$ \\
\hline Vitamin B6 & $41.14 \mathrm{mg}$ \\
\hline Vitamin B12 & $50 \mathrm{mcg}$ \\
\hline Biotin & $50 \mathrm{mcg}$ \\
\hline Folic acid & $500 \mathrm{mcg}$ \\
\hline Vitamin C & $165.2 \mathrm{mg}$ \\
\hline Choline bitartrate & $25 \mathrm{mg}$ \\
\hline Inositol & $25 \mathrm{mg}$ \\
\hline Citrus bioflavonoid extract & $40 \mathrm{mg}$ \\
\hline Lysine & $50 \mathrm{mg}$ \\
\hline Calcium & $42 \mathrm{mg}$ \\
\hline Magnesium & $47.16 \mathrm{mg}$ \\
\hline Potassium & $2 \mathrm{mg}$ \\
\hline Iron & $4.9 \mathrm{mg}$ \\
\hline Chromium & $6.2 \mathrm{mcg}$ \\
\hline Manganese & $1.6 \mathrm{mg}$ \\
\hline Copper & $58 \mathrm{mcg}$ \\
\hline lodine & $50.46 \mathrm{mcg}$ \\
\hline Zinc & $5 \mathrm{mg}$ \\
\hline Selenium & $26 \mathrm{mcg}$ \\
\hline Co-Enzyme Q10 & $1 \mathrm{mg}$ \\
\hline Spearmint oil & $1.5 \mathrm{mg}$ \\
\hline Parsley & $10 \mathrm{mg}$ \\
\hline Papaya & $10 \mathrm{mg}$ \\
\hline Lutein & $200 \mathrm{mcg}$ \\
\hline Celery & $20 \mathrm{mg}$ \\
\hline Astragalus & $50 \mathrm{mg}$ \\
\hline Siberian Ginseng & $25 \mathrm{mg}$ \\
\hline Bearberry & $25 \mathrm{mg}$ \\
\hline Gotu kola & $10 \mathrm{mg}$ \\
\hline Hawthorn & $30 \mathrm{mg}$ \\
\hline Horsetail & $30 \mathrm{mg}$ \\
\hline Fennel & $15 \mathrm{mg}$ \\
\hline Chamomile & $15 \mathrm{mg}$ \\
\hline Licorice & $10 \mathrm{mg}$ \\
\hline Ginger & $15 \mathrm{mg}$ \\
\hline Globe artichoke & $50 \mathrm{mg}$ \\
\hline Oats & $500 \mathrm{mg}$ \\
\hline
\end{tabular}

Table 2 Women's SMV preparation contents (Continued)

\begin{tabular}{ll}
\hline Bilberry & $25 \mathrm{mg}$ \\
Grape seed & $1 \mathrm{~g}$ \\
St Mary's thistle & $50 \mathrm{mg}$ \\
Ginkgo & $5 \mathrm{mg}$ \\
Green tea & $20 \mathrm{mg}$ \\
Tomato & $700 \mathrm{mg}$ \\
\hline
\end{tabular}

To provide increased scientific rigour, a quantitative analysis was performed to compare the frequency with which themes were reported within treatment groups. For each participant every theme was coded as having been "reported" or "not reported". Using this categorical classification a Chi Square analysis was then conducted for each theme, with significance set at a $p<.05$, while a trend towards significance regarded as between $p$ of .05 and .10 . These analyses were then repeated separately within genders.

\section{Results}

Sample

A total of 182 participants were enrolled in the study, of these 138 received treatment. An attrition rate of approximately $16 \%$ was observed, with 116 participants completing the study (Figure 1). Qualitative data was available from 114 participants, 59 from the placebo group and 55 from the SMV group. A count of returned tablets indicated that all participants satisfied the $80 \%$ compliance requirement at their final visit. The characteristics of the sample (Table 3) revealed that the mean age of participants was early 30s, they were educated and had higher than average intelligence, low depression and anxiety levels, and an average BMI (for adult Australians). The two treatment groups did not differ significantly on any examined demographic characteristic, either in the sample as a whole or when split by gender.

\section{Overview of qualitative data}

The qualitative data were divided into "Positive Effects" or "Negative Effects" and coded into four primary domains, in addition to supplementary analysis of any unusual experiences. A total of 21 further emergent themes were found and coded under these main domains (see Table 4). Examples of participants' experiences are detailed below. Statements are provided that best represent the themes revealed from qualitative analysis. As a result, some participants' responses are not included, while others are quoted more than once.

\section{Summary of positive and negative experiences}

In response to the question posed to participants about any positive effects, the majority of participants (60.0\%) 


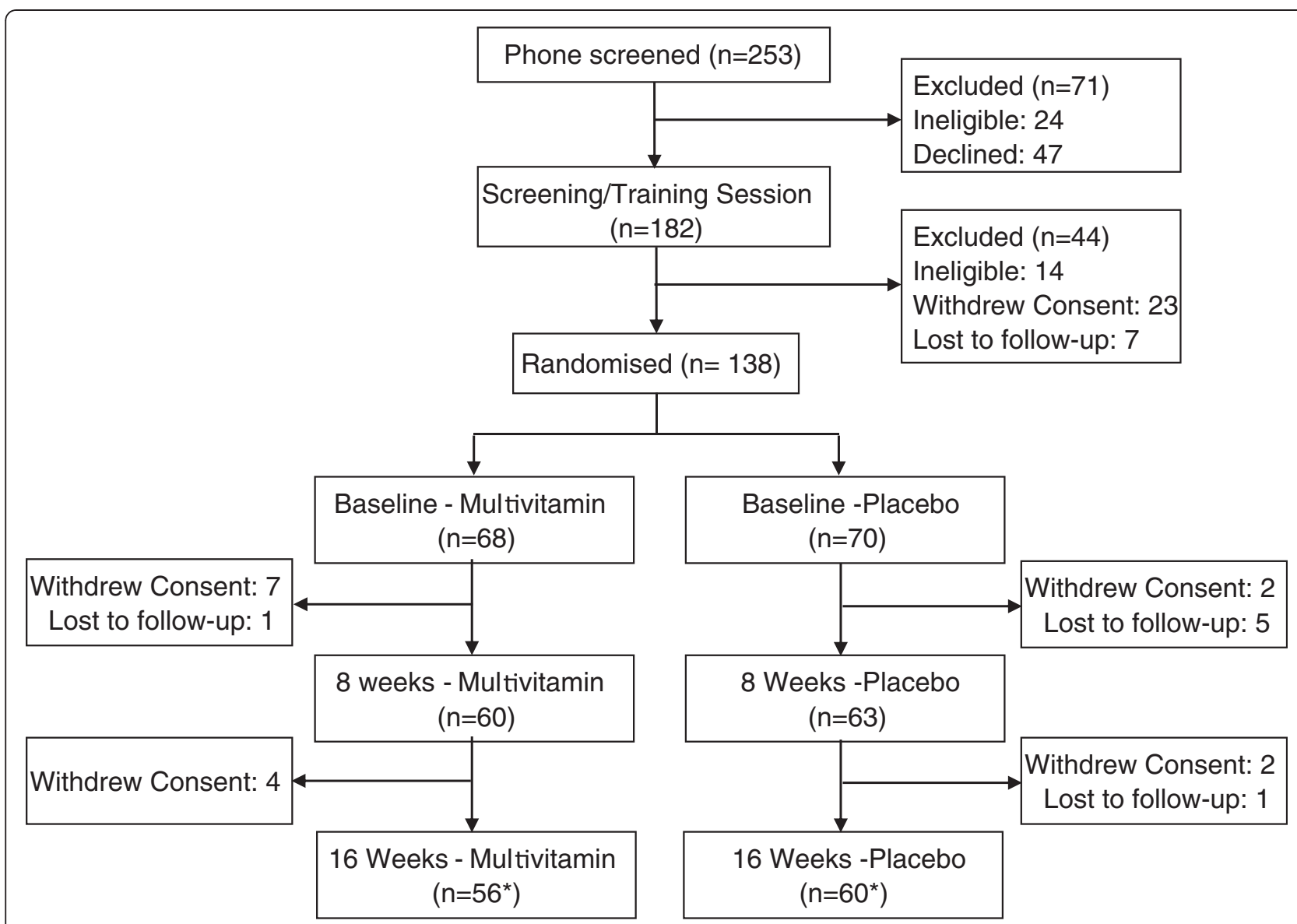

Figure 1 Trial design and visit completion. ${ }^{*}$ One participant from the Multivitamin group and one participant from the Placebo group failed to provide qualitative data.

in the SMV group reported at least one positive experience compared to those in the placebo group (50.8\%; Table 5). In the area of positive reported effects, the two main statistically significant themes identified in the SMV group over the placebo group were an increase in energy and mental alertness, and an increase in mood and mental/emotional wellbeing. More people in the SMV group reported sleep improvement compared to placebo, but due to low power the result did not reach statistical significance. Curiously, two participants reported a beneficial change in appetite, while one person (placebo group) said their skin was better. Of the negative effects reported, no significant differences were found between SMV and placebo (further detail below).

\section{Multivitamin effects on energy levels}

A total of $17.2 \%$ more participants in the SMV group significantly reported increased energy levels and mental alertness compared to the placebo group $(p=.022)$. Females in the SMV group significantly $(p=.020)$ reported experiences of increased energy and mental alertness than females in the placebo group $(22.5 \%$ difference). Positive perceived effects on participant's energy levels commonly reported in the SMV group included:

"More alert, bright, full of energy"

"I found getting up early. . easier"

"Have felt like I have more energy"

"I feel some sort of relaxation and energy"

"My energy levels were quite good over the period and I felt happy most of the time"

"A general feeling of more alertness particularly in the morning"

"I felt physically less tired"

\section{Multivitamin effects on mood and stress}

Compared with the placebo group, a total of $15.1 \%$ more participants in the SMV group reported the experience of better mood and emotional state. This difference was statistically significant $(p=.027)$. While nearly $20 \%$ more 
Table 3 Baseline characteristics of participants $(n=114) *$

\begin{tabular}{|c|c|c|c|c|c|c|}
\hline Gender & Age & Education & Intelligence & BMI & Trait Anxiety & Depression \\
\hline \multicolumn{7}{|l|}{ Placebo } \\
\hline Male & $30.93(7.47)$ & $17.00(2.57)$ & $28.43(2.70)$ & $26.13(4.98)$ & $31.00(6.15)$ & 3.82 (3.78) \\
\hline Female & $30.80(6.46)$ & $17.71(3.14)$ & $28.87(2.25)$ & $22.03(5.59)$ & $34.52(7.84)$ & $3.71(4.04)$ \\
\hline Total & $30.86(6.90)$ & $17.37(2.88)$ & $28.66(2.46)$ & $23.98(5.65)$ & $32.85(7.25)$ & $3.76(3.89)$ \\
\hline \multicolumn{7}{|c|}{ Multivitamin } \\
\hline Male & $28.91(6.90)$ & $16.38(1.86)$ & $29.29(3.18)$ & $24.41(3.21)$ & $34.54(9.43)$ & $5.29(4.67)$ \\
\hline Female & $32.94(7.85)$ & $17.71(3.07)$ & $28.13(2.91)$ & $23.98(5.31)$ & $32.68(7.13)$ & $4.61(5.04)$ \\
\hline Total & $31.18(7.76)$ & $17.13(2.67)$ & 28.65 (3.06) & $24.47(4.46)$ & 33.49 (8.18) & $4.91(4.85)$ \\
\hline \multicolumn{7}{|l|}{ All } \\
\hline Male & $30.00(7.20)$ & $16.71(2.27)$ & $28.83(2.94)$ & $25.34(4.30)$ & $32.63(7.96)$ & $4.50(4.24)$ \\
\hline Female & $31.87(7.21)$ & $17.71(3.08)$ & $28.51(2.60)$ & $22.99(5.50)$ & 33.60 (7.49) & $4.16(4.56)$ \\
\hline Total & $31.02(7.24)$ & $17.25(2.77)$ & $28.65(2.75)$ & $24.07(5.10)$ & $33.16(7.69)$ & $4.32(4.40)$ \\
\hline
\end{tabular}

* Data from participants randomized conditions; Data depicted as means and standard deviations; Education= Years of study; Intelligence = Matrix reasoning score; Trait Anxiety = State-Trait Anxiety Inventory-Trait Scale Score; Depression = Beck Depression Inventory-II score.

female participants reported an improvement of mood in the SMV compared to control, the result did not reach significance $(p=.054)$. Examples of beneficial experiences reported by the SMV group in the area of enhanced mood and reduced stress were:

"I feel a bit more carefree and I stress less"

"I have felt more relaxed; mood is more stable, less ups and downs"

"Stress levels have reduced... Feel calmer"

"Mood more uplifted"

"Much more calm than before taking this"

"Mood-wise I think I am more patient"

Table 4 Experiential themes identified

\begin{tabular}{|c|c|}
\hline Positive experience & Negative effect \\
\hline $\begin{array}{l}\text { Mental/Cognitive Domain } \\
\text { General Mental Benefit }\end{array}$ & $\begin{array}{l}\text { Mental/Cognitive Domain } \\
\text { Impaired Concentration/Attention }\end{array}$ \\
\hline $\begin{array}{l}\text { Improved Concentration, } \\
\text { Attention \&/or Memory }\end{array}$ & Stressed or Anxious \\
\hline Increased Calmness or Relaxation & More Moody and Emotional \\
\hline Better Mood \& Emotional State & Physical Domain \\
\hline Physical Domain & Impaired Sleep \\
\hline General Physical Benefit & More Fatigued \&/or Drowsy \\
\hline Improved sleep & Poorer Health \&/or Immunity \\
\hline More Energetic \&/or Alert & Upper Gastrointestinal complaint \\
\hline Better Health \&/or Immunity & Indigestion or Nausea \\
\hline Dermatological Benefit & Dermatological Complaint \\
\hline \multirow[t]{2}{*}{ Increased/Better Appetite } & Gynaecological Effect \\
\hline & Weight Gain \\
\hline
\end{tabular}

\section{Multivitamin effects on sleep}

Another theme that emerged was the experience by some participants of an improvement in their sleep. While $10 \%$ more participants in the SMV group reported a positive effect on sleep, this was just outside of significance $(p=.087)$. Examples of beneficial effects in the SMV group:

"Less tired/easier to fall asleep"

"Sleep quite peaceful... Increased my sleep during the night"

"Felt that tablets assisted in helping to sleep"

"Better sleep, less stress, more energy during the day time"

\section{Perceived negative experiences}

Importantly, no major adverse effects or reactions emerged from our thematic analysis, providing additional support for the quantitative finding that SMV was well tolerated by this sample. Overall SMV was well-tolerated with no statistical difference in the number of overall negative effects reported between the placebo $(28.8 \%)$ and MV (30.9\%) groups. Negative mental effects were not different between groups. Specifically, three females reported feeling more 'moody' or 'emotional' compared to none in the placebo group. Five participants experienced impaired concentration/alertness (two SMV, three placebo) three were more stressed or anxious (two SMV, one placebo), however this was not significantly different between groups.

Several participants reported experiencing mild negative physical reactions that occurred during the study. The most common complaint related to participants feeling dehydrated or need to drink soon after taking the tablets; experiencing heartburn; or an unpleasant taste. 
Table 5 Differential positive and negative effects experienced by participants

\begin{tabular}{|c|c|c|c|c|c|c|}
\hline & \multicolumn{2}{|c|}{ Full sample } & \multicolumn{2}{|c|}{ Males } & \multicolumn{2}{|c|}{ Females } \\
\hline & Placebo & Multi & Placebo & Multi & Placebo & Multi \\
\hline & $\mathrm{n}=59$ & $n=55$ & $n=28$ & $\mathrm{n}=\mathbf{2 4}$ & $\mathrm{n}=\mathbf{3 1}$ & $\mathbf{n}=31$ \\
\hline Positive experience & $50.8 \%$ & $60.0 \%$ & $64.3 \%$ & $62.5 \%$ & $38.7 \%$ & $58.1 \%$ \\
\hline \multicolumn{7}{|l|}{ Mental/Cognitive Domain } \\
\hline General Mental Benefit & $8.5 \%$ & $9.1 \%$ & $7.1 \%$ & $0.0 \%$ & $9.7 \%$ & $16.1 \%$ \\
\hline Improved Concentration, Attention \&/or Memory & $8.5 \%$ & $9.1 \%$ & $10.7 \%$ & $20.8 \%$ & $6.5 \%$ & $0.0 \%$ \\
\hline Increased Calmness or Relaxation & $20.3 \%$ & $14.5 \%$ & $21.4 \%$ & $25.0 \%$ & $19.4 \%$ & $6.5 \%$ \\
\hline Better Mood \& Emotional State & $8.5 \%$ & $23.6 \% *$ & $7.1 \%$ & $16.7 \%$ & $9.7 \%$ & $29.0 \% \#$ \\
\hline \multicolumn{7}{|l|}{ Physical Domain } \\
\hline General Physical Benefit & $8.5 \%$ & $5.5 \%$ & $14.3 \%$ & $12.5 \%$ & $3.2 \%$ & $0.0 \%$ \\
\hline Improved Sleep & $5.1 \%$ & $15.5 \% \#$ & $3.6 \%$ & $8.3 \%$ & $6.5 \%$ & $19.4 \%$ \\
\hline More Energetic \&/or Alert & $11.9 \%$ & $29.1 \% * *$ & $17.9 \%$ & $29.2 \%$ & $6.5 \%$ & $29.0 \% * * *$ \\
\hline Better Health \&/or Immunity & $6.8 \%$ & $10.9 \%$ & $10.7 \%$ & $8.3 \%$ & $3.2 \%$ & $12.9 \%$ \\
\hline Dermatological Benefit & $1.7 \%$ & $0.0 \%$ & $3.6 \%$ & $0.0 \%$ & $0.0 \%$ & $0.0 \%$ \\
\hline Increased/Better Appetite & $1.7 \%$ & $1.8 \%$ & $3.6 \%$ & $4.2 \%$ & $0.0 \%$ & $0.0 \%$ \\
\hline Negative experience & $28.8 \%$ & $30.9 \%$ & $25.0 \%$ & $25.0 \%$ & $32.3 \%$ & $35.5 \%$ \\
\hline \multicolumn{7}{|l|}{ Mental/Cognitive Domain } \\
\hline Impaired Concentration/Attention & $5.1 \%$ & $3.6 \%$ & $3.6 \%$ & $4.2 \%$ & $6.5 \%$ & $3.2 \%$ \\
\hline Stressed or Anxious & $1.7 \%$ & $3.6 \%$ & $0.0 \%$ & $0.0 \%$ & $3.2 \%$ & $6.5 \%$ \\
\hline More Moody and Emotional & $1.7 \%$ & $5.5 \%$ & $3.6 \%$ & $0.0 \%$ & $0.0 \%$ & $9.7 \%$ \\
\hline \multicolumn{7}{|l|}{ Physical Domain } \\
\hline Impaired Sleep & $1.7 \%$ & $1.8 \%$ & $3.6 \%$ & $0.0 \%$ & $0.0 \%$ & $3.2 \%$ \\
\hline More Fatigued \&/or Drowsy & $6.8 \%$ & $5.5 \%$ & $7.1 \%$ & $8.3 \%$ & $6.5 \%$ & $3.2 \%$ \\
\hline Poorer Health \&/or Immunity & $1.7 \%$ & $1.8 \%$ & $3.6 \%$ & $0.0 \%$ & $0.0 \%$ & $3.2 \%$ \\
\hline Upper Gastrointestinal complaint & $1.7 \%$ & $9.1 \%$ & $0.0 \%$ & $8.3 \%$ & $3.2 \%$ & $9.7 \%$ \\
\hline Indigestion or Nausea & $1.7 \%$ & $3.6 \%$ & $0.0 \%$ & $4.2 \%$ & $3.2 \%$ & $3.2 \%$ \\
\hline Dermatological Complaint & $1.7 \%$ & $1.8 \%$ & $0.0 \%$ & $4.2 \%$ & $3.2 \%$ & $0.0 \%$ \\
\hline Gynaecological Effect & $0.0 \%$ & $3.6 \%$ & - & - & $0.0 \%$ & $6.5 \%$ \\
\hline Weight Gain & $3.4 \%$ & $1.8 \%$ & $3.6 \%$ & $0.0 \%$ & $3.2 \%$ & $3.2 \%$ \\
\hline
\end{tabular}

${ }^{*}{ }^{2}(1)=4.921, p=0.027 ;{ }^{* *} X_{(1)}^{2}=5.245, p=0.022 ;{ }^{* * *} X_{(1)}^{2}=5.415, p=0.020{ }^{\#} p=0.05-0.10$ (trend).

While 7\% more participants in the SMV than the placebo group reported mild negative gastrointestinal effects, this was just outside of statistical significance $(p=.077)$. Another negative experience included two females in the SMV noting they had a negative gynaecological effect (one perceived an increase in premenstrual symptoms, and the other a change in her menstrual cycle). Two participants in the placebo group and one participant in the multivitamin group reported weight gain. Impaired sleep, dermatological complaints (rash or dry skin/nails) and more frequent illness were each reported by single participants in both groups.

\section{Unusual experiences reported}

Six unusual effects were reported by participants, although it cannot be determined whether these experiences were related to either group's intervention. For the SMV group, three unusual effects were reported: "Early on I felt that I sweated more - under the arms" "Faeces more hard perhaps" "Sensitive to the room temperature when sleeping".

A total of 3 people in the placebo group reported unusual effects: "I experienced fuzzy eyes" "Several mornings I woke up with a headache" "Kidney-ache occurred for the last six weeks. . Quite intense about 4 weeks ago".

\section{Discussion}

Results of the first exploratory qualitative assessment of participants' experiences of chronic daily administration of a multivitamin (MV) revealed significant effects in several areas. The major significant themes found between SMV and placebo concerned participants' 
perceived increased energy levels and enhanced mood, with a trend towards some experiencing better sleep. We performed a double-blind analysis and utilised quantitative methods of data analysis (i.e. Chi square test), increasing confidence in these results.

While assessment on quantitative numerical assessment scales is considered the "gold standard", use of qualitative methods, involving data from open-ended questions, clinician's notes, and forums, may reveal outcomes that may not have been found by established quantitative assessment tools. This method has been used successfully in other nutraceuticals studies [34,35], but not yet for MV studies. As commented by Berk et al. [35], unexpected but important phenomena may escape detection in purely quantitative studies. In their doubleblind RCT involving the application of $\mathrm{N}$-acetyl cysteine for schizophrenia, emergent themes arose which had not been captured by the quantitative rating scales utilised. Such identified novel effects can potentially factor into future practice guidelines, or can be specifically studied in subsequent RCTs.

The finding of participants reporting significantly increased mood and energy is in line with results of previous MV and B vitamin complex research; adequate $B$ vitamin levels are critical for neuronal communication and energy generation. Importantly, very few participants experienced any negative effects, and no significant adverse reactions were identified in the study. The only cases of identified side effects concerned minor gastrointestinal symptoms; reactions such as nausea have been previously reported by a small percentage of the general public who take a MV [36]. Analysis by gender revealed that the observed benefit on mood and energy were more likely to be experienced by women than men.

Limitations of the qualitative component are acknowledged. The use of a written semi-structured assessment form does not provide the rich exploration of experience that can achieved from interviews with open-ended questions or focus groups, and the small sample size meant that only very common effects of SMV could be reliably detected. Additionally as the qualitative questions addressed perception of change due to treatment they were only completed at the final testing visit. An intent-to-treat analysis was therefore not possible for this data and only study completers were included in the analysis.

It should be noted that these analyses have not be corrected for multiple comparisons. When multiple outcome measures, such as our 21 themes, are assessed, a $\mathrm{p}$-value correction may not always be the best approach as it can result in an overly conservative significance level and increased likelihood of a Type 2 error [37]. The themes seen here to benefit from multivitamin use are supported theoretically and by the supplementation effects seen in previous quantitative studies.

The qualitative data presented here provides the first exploration of the important topic of participants' experiences and should prompt further, more in-depth investigation of this topic as part of future RCTs.

\section{Conclusions}

This paper represents the first documented qualitative investigation of participants' experience of chronic administration of a multivitamin. Overall the exploratory experiential data provided by the participants was found to reflect the general findings of previous quantitative trial data; multivitamin supplementation may be associated with appreciable mood enhancement and increases in energy even in a normal, non-depressed and non-anxious population. Future RCTs are encouraged to adopt a similar mixed-methods approach.

\section{Abbreviations}

MV: Multivitamin; RCT: Randomised controlled trial; SMV: Swisse Men's Ultivite $\mathrm{F} 1^{\circledR} /$ Swisse Women's Ultivite $\mathrm{F} 1{ }^{\circledR}$.

\section{Competing interests}

The National Institute of Integrative Medicine, of which Professor Avni Sali is currently director, receives financial support from Swisse Vitamins Pty Ltd. Andrew Pipingas and Avni Sali are currently members of the Scientific Advisory Board for Swisse Vitamins Pty Ltd. Aside from oversight of study design and provision of supplements, Swisse Vitamins Pty Ltd were not involved in any other aspects of the conduct of the trial including analysis, or interpretation of the trial findings.

\section{Authors' contributions}

JS contributed to data analysis and interpretation and prepared the manuscript. KC collected data, conducted data analysis and interpretation and contributed to the manuscript writing. DAC, AS, CS, MK, AS and AP contributed to study conception and design and to manuscript revision. DJW and EF collected data and contributed to manuscript revisions. All authors have read and approved the final version of the manuscript.

\section{Acknowledgements}

The funding body for this trial was Swisse Vitamins Pty Ltd. Dr Jerome Sarris is funded by an Australian National Health \& Medical Research Council fellowship (NHMRC funding ID 628875), in a strategic partnership with The University of Melbourne, NICM Collaborative Research Centre in Neurocognition, and The Centre for Human Psychopharmacology at Swinburne University of Technology.

\section{Author details}

${ }^{1}$ Department of Psychiatry, The University of Melbourne, Melbourne, Australia. ${ }^{2}$ Centre for Human Psychopharmacology, Swinburne University of Technology, Hawthorn, Australia. ${ }^{3}$ Brain and Psychological Sciences Research Centre, Swinburne University of Technology, Hawthorn, Australia. ${ }^{4}$ National Institute of Integrative Medicine, Hawthorn, Australia.

Received: 7 August 2012 Accepted: 30 November 2012

Published: 14 December 2012

\section{References}

1. Kelly JP, Kaufman DW, Kelley K, Rosenberg L, Anderson TE, Mitchell AA: Recent trends in use of herbal and other natural products. Arch Intern Med 2005, 165(3):281-286.

2. Haskell CF, Scholey AB, Jackson PA, Elliott JM, Defeyter MA, Greer J, Robertson BC, Buchanan T, Tiplady B, Kennedy DO: Cognitive and mood effects in healthy children during 12 weeks' supplementation with multi-vitamin/minerals. Br J Nutr 2008, 100(5):1086-1096. 
3. Kennedy DO, Veasey R, Watson A, Dodd F, Jones E, Maggini S, Haskell CF: Effects of high-dose $B$ vitamin complex with vitamin $C$ and minerals on subjective mood and performance in healthy males. Psychopharmacology 2010, 211(1):55-68.

4. Benton D, Haller J, Fordy J: Vitamin supplementation for 1 year improves mood. Neuropsychobiology 1995, 32(2):98-105.

5. Schlebusch L, Bosch BA, Polglase G, Kleinschmidt I, Pillay BJ, Cassimjee MH: A double-blind, placebo-controlled, double-centre study of the effects of an oral multivitamin-mineral combination on stress. South African Medical J 2000, 90(12):1216-1223.

6. Carroll D, Ring C, Suter M, Willemsen G: The effects of an oral multivitamin combination with calcium, magnesium, and zinc on psychological well-being in healthy young male volunteers: a double-blind placebocontrolled trial. Psychopharmacology 2000, 150(2):220.

7. Harris E, Kirk J, Rowsell R, Vitetta L, Sali A, Scholey A, Pipingas A: The effect of multivitamin supplementation on mood and stress in a group of healthy older males. Hum Psychopharmacol Clin Exp 2011, 26(8):560-567.

8. Gariballa S, Forster S: Effects of dietary supplements on depressive symptoms in older patients: A randomised double-blind placebocontrolled trial. Clin Nutr 2007, 26(5):545-551.

9. Grima NA, Pase MP, Macpherson H, Pipingas A: The Effects of Multivitamins on Cognitive Performance: A Systematic Review and Meta-Analysis. J Alzheimers Dis 2012, 29(3):561-569.

10. Harris E, Macpherson H, Vitetta L, Kirk J, Sali A, Pipingas A: Effects of a multivitamin, mineral and herbal supplement on cognition and blood biomarkers in older men: a randomised, placebo-controlled trial. They also contain a range of antioxidants and extracts equivalent to approximately $2.6-3 \mathrm{~g}$ of medicinal herbs including. Hum Psychopharmacol Clin Exp 2012, 27(4):370-377.

11. Miller AL: The methionine-homocysteine cycle and its effects on cognitive diseases. Altern Med Rev 2003, 8(1):7-19.

12. Elias MF, Robbins MA, Budge MM, Elias PK, Brennan SL, Johnston C, Nagy Z, Bates CJ: Homocysteine, folate, and vitamins B6 and B12 blood levels in relation to cognitive performance: The Maine-Syracuse study. Psychosom Med 2006, 68(4):547-554.

13. Tolmunen $T$, Voutilainen $S$, Hintikka J, Rissanen $T$, Tanskanen A, Viinamaki $H$, Kaplan GA, Salonen JT: Dietary Folate and Depressive Symptoms Are Associated in Middle-Aged Finnish Men. J Nutr 2003, 133(10):3233-3236.

14. Alpert JE, Mischoulon D, Nierenberg AA, Fava M: Nutrition and depression: focus on folate. Nutrition 2000, 16(7-8):544-546.

15. Baldewicz T, Goodkin K, Blaney NT, Shor-Posner G, Kumar M, Wilkie FL, Baum MK, Eisdorfer C: Cobalamin level is related to self-reported and clinically rated mood and to syndromal depression in bereaved HIV-1+ and HIV-1- homosexual men. J Psychosom Res 2000, 48(2):177-185.

16. Engelhart MJ, Geerlings MI, Ruitenberg A, Van Swieten JC, Hofman A, Witteman JCM, Breteler MMB: Dietary intake of antioxidants and risk of Alzheimer disease. J Am Med Assoc 2002, 287(24):3223-3229.

17. Harrison FE, May JM: Vitamin C function in the brain: vital role of the ascorbate transporter SVCT2. Free Radic Biol Med 2009, 46(6):719-730.

18. Lansdowne ATG, Provost SC: Vitamin D3 enhances mood in healthy subjects during winter. Psychopharmacology 1998, 135(4):319-323.

19. Holick MF: Vitamin D Deficiency. N Eng J Med 2007, 357(3):266-281.

20. Black J, Piñero DJ, Parekh N: Zinc and cognitive development in children: Perspectives from international studies. Topics in Clin Nutr 2009, 24(2):130-138.

21. Cardoso CC, Lobato KR, Binfaré RW, Ferreira PK, Rosa AO, Santos ARS, Rodrigues ALS: Evidence for the involvement of the monoaminergic system in the antidepressant-like effect of magnesium. Prog Neuropsychopharmacol Biol Psychiatry 2009, 33(2):235-242.

22. Gareri P, Mattace R, Nava F, De Sarro G: Role of calcium in brain aging. Gen Pharmacol 1995, 26(8):1651-1657

23. Rai D, Bhatia G, Sen T, Palit G: Anti-stress Effects of Ginkgo biloba and Panax ginseng: a Comparative Study. J Pharmacol Sci 2003, 93(4):458-464.

24. Woelk H, Arnoldt KH, Kieser M, Hoerr R: Ginkgo biloba special extract EGb $761^{\circledR}$ in generalized anxiety disorder and adjustment disorder with anxious mood: A randomized, double-blind, placebo-controlled trial. J Psychiatr Res 2007, 41(6):472-480.

25. Wattanathorn J, Mator L, Muchimapura S, Tongun T, Pasuriwong O, Piyawatkul N, Yimtae K, Sripanidkulchai B, Singkhoraard J: Positive modulation of cognition and mood in the healthy elderly volunteer following the administration of Centella asiatica. J Ethnopharmaco/ 2008, 116(2):325-332.

26. Macpherson $H$, Ellis KA, Sali A, Pipingas A: Memory improvements in elderly women following 16 weeks treatment with a combined multivitamin, mineral and herbal supplement. Psychopharmacology 2012 220:351-365.

27. Aldridge D: Qualitative methods in CAM research. London: Routledge; 2007.

28. Schumacher KL, Koresawa S, West C, Dodd M, Paul SM, Tripathy D, Koo P, Miaskowski C: Qualitative research contribution to a randomized clinical trial. Res Nurs Health 2005, 28(3):268-280.

29. Rowlands G, Sims J, Kerry S: A lesson learnt: the importance of modelling in randomized controlled trials for complex interventions in primary care. Fam Pract 2005, 22(1):132-139.

30. National Health and Medical Research Council: In Nutrient Reference Values for Australia and New Zealand Including Recommended Dietary Intakes. Edited by Australian Government Department of Health and Ageing. Canberra: Commonwealth of Australia; 2005:317.

31. Spielberger CD, Gorsuch RL, Lushene RE: STAl: Manual for the state-trait anxiety inventory. Palo Alto, CA: Consulting Psychologists Press; 1969.

32. Beck AT, Steer RA, Brown GK: BDI-II, Beck depression inventory: manua. 2nd edition. Boston: Harcourt Brace; 1996.

33. Wechsler D: The Wechsler Abbreviated Scale of Intelligence (WASI). San Antonio, TX: Harcourt Assessment; 1999

34. Sarris J, Adams J, Kavanagh D: An explorative qualitative analysis of participants' experience of using kava versus placebo in an RCT. Aust J Med Med Herbalism 2010, 22(1):12-16.

35. Berk M, Munib A, Dean O, Malhi GS, Kohlmann K, Schapkaitz I, Jeavons S, Katz F, Anderson-Hunt M, Conus P, et al: Qualitative methods in early-phase drug trials: broadening the scope of data and methods from an RCT of N-acetylcysteine in schizophrenia. J Clin Psychiatry 2011, 72(7):909-913.

36. Timbo BB, Ross MP, McCarthy PV, Lin CT: Dietary supplements in a national survey: Prevalence of use and reports of adverse events. J Am Diet Assoc 2006, 106(12):1966-1974.

37. Feise RJ: Do multiple outcome measures require p-value adjustment? BMC Med Res Methodol 2002, 2(8). doi:10.1186/1471-2288-2-8.

\section{doi:10.1186/1475-2891-11-110}

Cite this article as: Sarris et al:: Participant experiences from chronic administration of a multivitamin versus placebo on subjective health and wellbeing: a double-blind qualitative analysis of a randomised controlled trial. Nutrition Journal 2012 11:110.

\section{Submit your next manuscript to BioMed Central and take full advantage of:}

- Convenient online submission

- Thorough peer review

- No space constraints or color figure charges

- Immediate publication on acceptance

- Inclusion in PubMed, CAS, Scopus and Google Scholar

- Research which is freely available for redistribution
C) BioMed Central 